\title{
A NOMOGRAM FOR USE IN INFANT FEEDING
}

\author{
BY
}

\author{
GEORGE H. BELL, M.B., Ch.B., B.Sc., \\ and A. CRAIG PATERSON.
}

(From the Dept. of Pædiatrics, Glasgow University, and the Royal Hospital for Sick Children, Glasgow.)

Exactness is the key-note of modern infant feeding. The neglect of this desideratum is the cause of much 'marasmus' through inanition. Graham Lusk $^{1}$ wrote in 1921 'The so-called scientific feeding of infants is unworthy of the name unless the caloric requirement is carefully considered. From lack of this knowledge babies are frequently systematically starved.'

The only objection to the adoption of such a method is that it necessitates the knowledge of certain facts ; for example, the weight and the rate of increase in weight of the infant, the caloric needs of the infant according to the state of its nutrition and age, and the caloric values of various foods. The estimation of the proper feed for any individual child thus requires a calculation, and it is towards the elimination of this labour that the following nomogram has been devised. From this nomogram it is not only possible to tell what the weight of a child at any individual age should be, the relative state of its nutrition, the caloric requirements, but also the amount of undiluted milk necessary to supply these.

The chart is constructed, as already said, on the principle of the nomogram. All the scales are divided logarithmically. It is to be noted that scales A and B increase from above downwards, while scales $\mathrm{D}$ and $\mathrm{E}$ decrease from above downwards.

It is suggested that the chart be mounted on a board and covered by a sheet of transparent celluloid. All the calculations are made by drawing straight lines across the chart. This can be done by means of a ruler or better by means of a thread stretched across the chart. It is recommended that the instructions ba typed and pasted on the back of the chart so that it may be readily available for routine work.

\section{Applications.}

1. To Find THE EXPeCted weight IN Kilogrammes.-If scale $\mathrm{B}_{2}$ is read off opposite the age in months on scale $B_{1}$ the figure so obtained is the expected weight in kilogrammes.

2. To FIND THE PERCENTAGE OF THE EXPECTED WEIGHT.-Join on scale $B_{1}$ the age of the child to the actual weight in kilogrammes on scale $E_{1}$. The point of intersection of the thread with scale $D_{1}$ will be the percentage of the expected weight. 
3. To Find THE TOtAL DAILY CALORIC REQUIREMENTS.-Join on scale $B_{1}$ the age in months to the appropriate number of calories per kgrm. of expected weight on scale $\mathbf{D}_{2}$. The point of intersection of the thread with scale $\mathbf{E}_{2}$ will be the total daily requirements.

4. To FIND THE CALORIES SUPPLIED PER KILOGRAMME OF EXPECTED Weight, GIVEN THE CALORIC VALUE OF THE DIET.-Join the number of calories supplied on scale $E_{2}$ to the age on scale $B_{1}$. The point of intersection of the thread with scale $\mathrm{D}_{2}$ gives the required value.

5. To FIND THE CALORIES SUPPLIED PER KILOGRAMME OF ACTUAL wEIGHT.-Join the number of calories supplied on scale $\mathrm{E}_{2}$ to the actual weight on scale $B_{2}$. The intersection with scale $D_{2}$ gives the required value.

6. To FIND THE VOLUME OF WHOLE MILK TO BE SUPPLIED.-Join the total daily caloric requirements as found under 3 to the intersection of the horizontal line marked ' Whole Milk' with the short vertical line (Scale C). The point at which the thread intersects scale $A_{1}$ or $A_{2}$ gives the amount of whole milk required in ounces or cubic centimetres respectively.

Notes.-If sugar is added to the milk, the daily caloric value of the sugar must be subtracted from the total daily requirements before calculating the volume to be supplied. Similarly the volume of peptonised milk or buttercurd mixture (B.C.M.) can be obtained by using the intersections marked 'Pept. Milk' or 'B.C.M.'

Butter.curd mixture (B.C.M.) is similar to Eiweiss milch of Finkelstein.

\section{REFERENCE.}

1. Lusk, G., Elements of the Science o Nutrition, Philadelphia, 1921, 3rd Ed., 404. 
ARCHIVES OF DISEASE IN CHILDHOOD

NOMOGRAM OF INFANT

FEEDING.

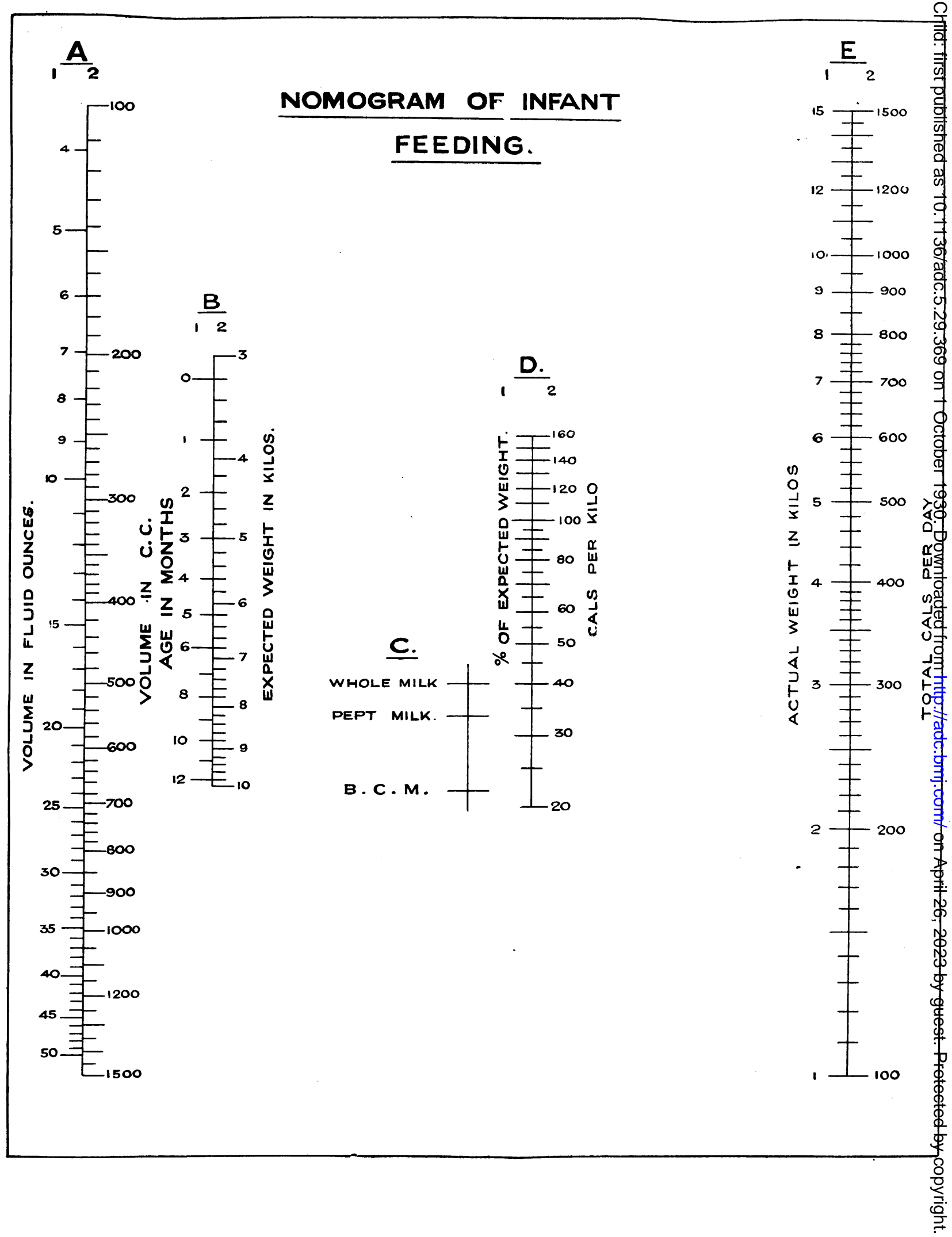

